\title{
EDITORIAL
}

\section{Reviewing the review}

\section{Sanjay N Jain}

Editor-in-Chief, The Indian Journal of Radiology and Imaging, Prince Aly Khan Hospital, Mumbai, Maharashtra, India. E-mail: dr.jainsn@gmail.com

\section{Dear colleagues,}

As I communicate with you through this penultimate issue, two thoughts simultaneously run in the four corners of my mind: The first is the way time has galloped for nearly the past 3 years and second, with the next issue (November 2015), I would have to bid good-bye to our fruitful association in my current capacity. Our journal, in its truest sense, has seen lots of development but we still have a long way to go.

If you would very kindly remember, I have had a penchant for the principal area of how to write an article in a journal and the continued thrust for creating the writers of tomorrow. Both these have very finely confluenced under one heading and that is how to review an article. While it is the earnest desire of every reviewer to help maintain the highest quality of articles that would be directly proportional to the character of the journal, many a time authors of such articles go by a misnomer that if their articles get rejected, the reviewer has done so by virtue of a bias that is hardly a case. In the good interest of putting an end to this unending question of what goes into reviewing articles by the reviewer, the August editorial has been exclusively devoted to this. This write-up is to make authors understand the approach in accepting or rejecting articles if they have been reviewed objectively ${ }^{[1]}$ In other words, the write-up is to make the author understand his/her outlook on that article. Another aspect that needs an in-depth understanding is that higher the standard of a journal, the more rigorous the review of the article for that journal.

You would be well-aware that for over three centuries, peer reviewers have been looked upon as the authority to review an article, based on which various authors have put forth their findings in professional forums and across the world. In the process of selecting or rejecting an article by peer reviewing, what needs to be understood here is that there

\begin{tabular}{|l|l|}
\hline \multicolumn{2}{|c|}{ Access this article online } \\
\hline Quick Response Code: & \\
\hline & Website: \\
\hline & www.ijri.org \\
\cline { 2 - 3 } & DOI: \\
\hline
\end{tabular}

are a lot of aspects that are at stake, which are not confined to reviewing the said article alone; these aspects include upholding the integrity of the journal that the reviewers are reviewing, fulfilling a sense of duty, establishing relationships and expertise, reciprocating courtesies, increasing their reputation by staying up-to-date, and learning about their discipline in depth by having access to the very latest research. This is not only applied to journals across the globe but also to IJRI as well.

What has been in vogue is the method of review, which is not by intuition but strictly by training and experience with which a reviewer reviews an article; this training and experience comes by virtue of trial and error but this cannot be a uniform method, even for a journal, since it has got different reviewers. The role of a reviewer is extremely important since once an article comes to him/her, the principal criterion is to weigh the merit of the article by global rating, i.e., accept, accept with pending revisions, reconsider after major revisions, and reject. The extended role also covers the task of constructive criticism of the authors with an intention of helping them understand what they have missed that the reviewer has seen - advising the author. ${ }^{[2]}$

Reviewing starts with the kind of approach with which the article is read by the reviewer. It could be superficial or in-depth. Following that, the most important criterion is the abstract that contains all the papers of the research work in original. The abstract primarily summarizes the article. Would a reviewer be able to read out a gist of what is in the article by going through the abstract matter largely? Insufficient, unnecessary, or vague manuscripts are to be likely looked down upon. Having said the above, the reviewer begins by looking at the introduction as to what the author is trying to notify and what can be expected in the article.

This is an open access article distributed under the terms of the Creative Commons Attribution-NonCommercial-ShareAlike 3.0 License, which allows others to remix, tweak, and build upon the work non-commercially, as long as the author is credited and the new creations are licensed under the identical terms.

For reprints contact: reprints@medknow.com

Cite this article as: Jain SN. Reviewing the review. Indian J Radiol Imaging 2015;25:211-2. 
The next step would be to figure out the method in which the article has been written. This is the area in which the author would highlight how the study has been undertaken. It gives the hypothesis based on which the study has been done. In a nutshell, it is the blueprint of the work done. Sometimes, authors fail to get the right study for methods and thus, they lose track. This follows the results section where the author has to elucidate his/her findings clearly. One point to remember is that if the analysis for the data is poorly executed, the article would be rejected outright but if the results section is poorly executed, it can be redone and accepted. This fundamental needs to be accepted here.

Following this is the discussion where the author has to provide quite lengthy explanations for the hypothesis-based questions and the results thereof. One also needs to make a mention of any discrepancy with any earlier results found in that regard and how the newfound result would be superior to the same. While a detailed explanation is warranted, it should not continue for long. Even while reviewing the medical literature, one has to focus on the point of relevance and not loose trail. The hallmark of a good manuscript is when an author helps bring out unexpected findings rather than ignore them. The case in reference here is about the usage of figures and graphs to highlight the important areas of the study. If they are well in place, the article would be indelibly etched in the reviewer's mind for assent. Apart from these, tables play a very important role in the comparison of data with reference to the study but they need to be used very judiciously since they consume sufficient space. References play a very important part as to how the author supports his findings but they should not be sidelined with his/ her own buttering of the article. In the age of electronic formats, the reviewer can quickly glance through the same in action. Finally, the summary is what is going to end the proceedings to the journey of the article so far. Reviewers need to look if the said manuscript is likely to add value to the already available medical literature or not. ${ }^{[3]}$

Moving on, the most important aspect after review would be to have the global rating of the manuscript. If it states "accept," the article is fit for publishing without any changes as it is. If the phrase is "accept pending revisions," it is implied that the manuscript can be accepted with due changes, which do not alter the principal content of the same. If the rating is "reconsider after major revision," major changes are warranted but they are not such that may come in the way of the publication of the article. Though, strictly speaking, an article cannot be published, in practice it gets so after major corrections. Finally, "reject" means that an article will not see the light of the day. It could also be since the manuscript has come to the wrong journal that was actually intended for some other journal, in our scenario perhaps a clinical journal.

After the review and ratings, the editor should go through the reviewers' ratings that boil down to two major areas; the informative review, which states that the reviewer has gone through the article in depth and the comments have a large bearing on the publication of the article and the noninformative one, wherein the reviewer may not come out with any substantial inputs warranting the editor to reject the article from the journal's point of view and at times even confusing the editor with a simultaneous confidential note over and above the observations on the manuscript. In other words, it drives the editor in an unknown direction.

All said and done, the final say on the articles, i.e., whether they are to be accepted or rejected lies with the editor.

The current issue includes a white paper on chest tuberculosis by Dr. Ashu Seith Bhalla, the first such paper from one of the new subspeciality heads. This article discusses the current state of knowledge, and goes through guidelines and protocols for the diagnosis and management of a disease that is still extremely prevalent in our country.

Financial support and sponsorship

Nil.

\section{Conflicts of interest}

There are no conflicts of interest.

\section{References}

1. Hoppin FG Jr. How I review an original scientific article. Am J Respir Crit Care Med 2002;166:1019-23.

2. Provenzale JM, Stanley RJ. A systematic guide to reviewing a manuscript. AJR Am J Roentgenol 2005;185:848-54.

3. Squires BP. Biomedical manuscripts: What editors want from authors and peer reviewers. CMAJ 1989;141:17-9. 